\title{
Gramsci e a Educação do Educador: a saída é Gramsciana. Não é Gramscista
}

\author{
Gramsci and Educator Education: the way out is Gramsciana. Not a Gramscista
}

\author{
Marília Gabriella Borges Machado \\ Universidade Estadual Paulista Júlio de Mesquita Filho (UNESP)
}

\begin{abstract}
Resumo: Este trabalho tem como objetivo principal acompanhar teoricamente a concepção de Antonio Gramsci relativa à autoeducação, enquanto um processo de autotransformação das classes subalternas. A metodologia é a análise crítica de artigos jornalísticos do jovem da Sardenha que remontam o período entre 1911 e 1920, além de sua obra carcerária e de importantes comentadores. Para tanto, compreender a relação entre educador e educando, questão essencial na construção da democracia operária e de uma nova forma de sociabilidade, nos leva a compreender um pouco do cenário brasileiro. Dessa maneira, o trabalho reflete a questão da autoeducação, do fascismo e da ideologia do gramscismo cultural, tendo como resultado principal a compreensão da necessidade de as classes subalternas construírem uma cultura própria, ligada ao trabalho, para emancipação popular. Portanto, a saída é gramsciana.
\end{abstract}

Palavras-chave: Gramsci; Autoeducação; Americanismo; Trabalho; Gramscismo.

\begin{abstract}
This work has as main objective to theoretically accompany Antonio Gramsci's conception of self-education, as a process of self-transformation of the subordinate classes. The methodology is the critical analysis of journalistic articles by the young man from Sardinia that go back to the period between 1911 and 1920, in addition to his prison work and important commentators. Therefore, understanding the relationship between educator and student, an essential issue in the construction of workers' democracy and a new form of sociability, leads us to understand a little of the Brazilian scenario. In this way, the work reflects the issue of self-education, fascism and the ideology of cultural gramscism, with the main result being the understanding of the need for the subordinate classes to build their own culture, linked to work, for popular emancipation. Therefore, the exit is Gramscian.
\end{abstract}

Keywords: Gramsci; Self-education; Americanism; Job; Gramscismo. 


\section{Introdução}

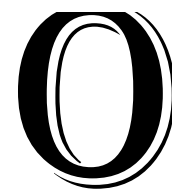

Brasil vive tempos incertos e obscuros. A conjuntura política nacional e internacional traz à tona o debate, mais do que necessário, sobre a obra de Antonio Gramsci. Muito se fala do intelectual comunista e muitos relacionam, equivocadamente, a obra gramsciana com os problemas que o país tem enfrentado. Seria Gramsci um dos intelectuais responsáveis pela guerra cultural, revolução cultural silenciosa e ameaça comunista que a esquerda instaurou no Brasil, de acordo com Olavo de Carvalho (2014), desde os anos 70.

É importante nos questionarmos sobre o poder de ideologia que Olavo de Carvalho $^{1}$ possui sobre tantas pessoas, inclusive o próprio Presidente da República, Jair Messias Bolsonaro. Além do poder ideológico, Olavo de Carvalho muito fala sobre Gramsci e seu processo de revolução cultural no Brasil, utilizam-se inúmeras vezes a expressão gramscismo cultural $^{2}$ para explanarem suas teorias conspiratórias. Em suma, para estes grupos, o debate científico se tornou mera teoria da conspiração controlada pela esquerda e questões, já antes comprovadas cientificamente, voltam junto com uma obscuridade, com discursos fundamentalistas e preconceituosos. A conversa das novas mídias sociais foi extrapolada para as instituições governamentais e têm novos interlocutores que transformam as tribunas em púlpitos. A ideologia gramscista até mesmo compreende que a educação no país segue uma linha de lavagem cerebral e de "conquista" para a esquerda, com a finalidade de criar um poder ditatorial, de o país se tornar algo semelhante com a Venezuela. A cada dia, os fenômenos conjunturais do Governo Bolsonaro comprovam que há, no Brasil, um movimento orgânico, quase permanente, de ausência democrática, além de seus discursos e entrevistas não demonstrarem nada diverso.

Mas, o que Gramsci efetivamente expressou? O que é a educação, a questão da cultura e a revolução para o jovem da Sardenha? E o principal, compreender que o projeto formado por Gramsci nada tem a ver com lavagem cerebral ou revolução cultural silenciosa, pois o proposto é a criação de uma nova democracia para a transformação e emancipação do subalterno?

\footnotetext{
1 Ver: CARVALHO, O. A nova era e a revolução cultural-Fritjof Capra e Antonio Gramsci. Vide: 2014. CARVALHO, O. O imbecil coletivo-atualidades inculturais brasileiras. Faculdade da Cidade Editora. Sétima Edição, 1999. COUTINHO, Sérgio. A revolução gramscista no ocidente: a concepção revolucionária de Antonio Gramsci em os Cadernos do Cárcere. Rio de Janeiro: Estandarte, 2002.

2 “Objetivo primeiro do gramscismo é muito amplo e geral em seu escopo: nada de política, nada de pregação revolucionária, apenas operar um giro de cento e oitenta graus na cosmovisão do senso comum, mudar os sentimentos morais, as reações de base e o senso das proporções, sem o confronto ideológico direto que só faria excitar prematuramente antagonismos indesejáveis.”. (CARVALHO, 2014, p.118).
} 
Dessa maneira, a partir da análise dos textos ${ }^{3}$ de Gramsci, é possível compreender que o autor desde seus primeiros escritos entendia ser de grande importância se debruçar sobre a questão educacional italiana, principalmente pela ausência de um projeto de educação socialista relacionado com a cultura por parte do Partido Socialista Italiano (PSI), o qual esteve filiado desde meados de 1913. Nos Cadernos do Cárcere, Gramsci muito escreveu sobre educação, sendo possível notar seu interesse nas Cartas do Cárcere, enquanto um projeto que se debruçaria a investigar.

Muitas foram às transformações na vida de Gramsci, mudanças que foram essenciais para sua elaboração teórico-política. Ao que se segue, em 1911 o jovem se mudara para Turim com o objetivo de cursar a Universidade, aos poucos se aproximava dos operários turineses e aumentava seu interesse para o cotidiano proletário, além de suas críticas ao modelo burguês universitário. Gramsci já compreendia, em meados de 1916, a necessidade de uma educação para o proletariado.

Será em 1917, com o entusiasmo da Revolução Bolchevique, que Gramsci se utiliza da questão da intransigência para compor o debate sobre a necessidade de o PSI cumprir um papel de disciplinador das massas e de educador da classe que representava. Os acontecimentos de 1919-1920 foram os mais importantes para fundamentar o exercício de tradutibilidade da revolução socialista na Rússia para a Itália, sendo necessário que os Conselhos de Fábrica se tornassem o embrião do Estado Operário. Os Conselhos passaram a se organizar como um organismo próprio do proletariado, fundado na democracia operária, na autoeducação, na autogestão do processo de produção e na criação do americanismo de tipo operário - de uma nova cultura --.

Em 1926, Gramsci é preso pela ditatura fascista de Benito Mussolini e, anos mais tarde, consegue permissão para escrever os conhecidos Cadernos do Cárcere. Em sua obra carcerária é possível encontrar muitas referências à educação e à questão escolar, todas estas questões voltada para seu projeto de emancipação do subalterno, com a essencialidade de as classes dominadas se tornarem agentes e protagonistas do processo revolucionário.

No entanto, sem a mínima pretensão de possuir alguma fundamentação teórica relevante e honesta, intelectualmente, alguns dos seguidores de Jair Bolsonaro e alunos de Olavo de Carvalho, guiados pela irracionalidade, pelo desinteresse histórico ao saber e à

\footnotetext{
${ }^{3}$ Os textos referenciados como (GRAMSCI, 1973) foram lidos/citados do livro Scriti Politici, organizados na íntegra por Paolo Spriano - contém artigos do período de 1916-1919. Referenciados como (GRAMSCI, 1954) fazem parte do livro Opere di Antonio Gramsci: L'Ordine Nuovo: 1919-1920, organizados e publicados pela Editora Einaud, na Itália. Os textos referenciados como (GRAMSCI, 1977, Q., \, p.) foram retirados dos Quaderni dal Carcere, a cura di V alentino Gerratana.
} 
ciência, transformam Gramsci em um teórico da estratégia gramscista. Para tanto, este artigo objetiva compreender: a) o que Gramsci expressou sobre a autoeducação e o princípio educativo no período entre 1915 e 1920; b) a questão do fascismo, com a finalidade de diferenciar o homem fascista, da classe subalterna que se emancipa - para Gramsci --, demonstrando a diferença pontual entre os princípios e ideologias; c) abranger brevemente sobre a atualidade do pensamento de Gramsci desenvolvido por Olavo de Carvalho e compreender a relação do gramscismo com o marxismo cultural. Tem como ponto de saída e conclusão que a estratégia e a saída é gramsciana, a partir da noção de autoeducação e de autogestão para criação de uma nova cultura e de uma nova sociabilidade, composta pelos trabalhadores.

\section{Desenvolvimento}

\section{Os homens e as máquinas}

O artigo Homens ou máquinas?, publicado em 24 de dezembro de 1916, no jornal Avantil, na coluna La scuola e $i$ socialisti, é uma das reflexões mais importantes de Gramsci sobre a questão escolar italiana. O sardo criticava a ausência de um projeto do PSI sobre a educação e um programa escolar concreto "que se diferencie dos tradicionais.". A Itália, por mais que tivesse diminuído os índices de analfabetismo, devia muito aos socialistas, que foram capazes de "suscitar", nas diversas camadas dos "proletários do povo italiano", o interesse pela educação e pela cultura. No entanto, "a escola continua a ser um organismo estritamente burguês, no pior sentido da palavra", de maneira que "a cultura é um privilégio", assim como "a escola é um privilégio.". A função do Estado deveria ser a de prover para os filhos de operários a mesma educação de qualidade que provia aos filhos da burguesia, independente da questão econômica, sendo necessário que os filhos dos operários pudessem se "dedicar tranquilamente" ao estudo "e poder estudar seriamente", sem se preocuparem com questões econômicas. (GRAMSCI, 1973, p. 81).

O proletariado, "excluído das escolas de cultura média e superior, por conta das atuais condições da sociedade, que determinam certa especialização dos homens", precisavam/precisam "ingressar nas escolas paralelas: técnicas e profissionais.". No entanto, estas escolas eram/são uma repetição "inútil das escolas clássicas, bem como um inocente desaguadouro para o empreguismo pequeno-burguês", de maneira que seguem, ainda hoje, na reprodução do proletariado e não de homens críticos e protagonistas da 
história. Continuam a formar máquinas e não homens críticos e conscientes. (GRAMSCI, 1973, p. 82).

Segundo Gramsci, a escola deveria cumprir a função de "uma escola desinteressada" e possibilitar o estudante a se formar também como pessoa de cultura, a partir de uma escola de liberdade "que não hipoteque o futuro da criança", mas que tenha possibilidades de formação diversas para que a criança seja capaz de "realizar sua própria individualidade da melhor forma e, por isso, do modo mais produtivo para eles e para a coletividade.". Para tanto, a escola profissional "não deve se transformar numa incubadora de pequenos monstros aridamente instruídos para um ofício, sem ideias gerais, sem alma, mas apenas com olho infalível e mão firme.”. É possível, de acordo com Gramsci, que a escola profissional pudesse "fazer brotar do menino um homem" por meio de uma “cultura educativa" e não somente "informativa" e "manual”. (GRAMSCI, 1973, p. 82-83).

Gramsci enfatiza, no final do texto, que para as classes dominantes é melhor que tenham mais operários-máquinas em vez de operários-homens. No entanto, se colocava na ordem do dia, para o Partido e para os proletários, lutarem por seus direitos, pois se tratava de um problema de "direito e de força" que beneficiaria a classe operária, no sentido de que a classe forja seus próprios intelectuais e constroem operários qualificados.

\subsection{Conselhos de Fábrica e autoeducação}

Nos anos seguintes, o Partido Socialista Italiano não foi capaz de organizar e disciplinar a massa italiana. Durante a Revolução Bolchevique (1917), Gramsci demonstrou muito entusiasmo com o processo revolucionário e notou a possibilidade de a Itália fazer como a Rússia. Os Sovietes de Petrogrado viriam a se tornar, em Turim - com suas singularidades --, os Conselhos de Fábrica.

Criados a partir das Comissões Internas, os Conselhos de Fábrica surgiam como frente antagônica ao economicismo dos Sindicatos - representados pela Confederazione Generale del Lavoro (CGL) - e às políticas reformistas do PSI. O papel central das Comissões Internas foi o de limitar o poder capitalista na fábrica. Os comissários executavam a função de árbitro e de disciplinadores a favor da classe operária, pois "a fábrica com suas comissões internas, e círculos socialistas, e comunidade campesina, são o centro da vida proletária na qual ocorre diretamente o trabalho.”. Dessa forma, "são órgãos de democracia operária", de "liberdade" do proletariado para as "limitações impostas" pelo patrão. (GRAMSCI, 1954, p. 11). Podem ser analisadas enquanto órgãos oriundos da ação 
espontânea do proletariado italiano, enquanto os Conselhos de Fábrica como a organização da vontade coletiva que se desenvolveu durante o processo revolucionário de 1919-1920.

Gramsci não gastou tempo e esforço para transformar as Comissões Internas em autênticos Soviets, não porque ele pensasse que a revolução russa deveria ser passivamente imitada, mas devido ao grande respeito pelos Conselhos que se espalharam por toda a Europa do pós-guerra e devido sua concepção geral da teoria socialista da revolução. (COMMETTI, 1974, p.110).

Para tanto, os Conselhos se tornaram um "organismo de controle" que transformaram o proletariado, de maneira "psicológica e técnica", além de possuírem o diferencial de ser a "base da vida comum" e o meio "através do qual os elementos revolucionários são capazes de afirmar a sua vontade de uma forma contínua e concreta”. (GRAMSCI, 1954, p.11). A questão psicológica - citada por Gramsci e por Angelo Tasca diversas vezes nos artigos de L'Ordine Nuovo - está relacionada com a questão da cultura ${ }^{4}$, que deve ser analisada a partir do nexo Conselhos de Fábrica - Autoeducação Cultura/Americanismo - Estado operário. O nexo entre, não apenas categorias ou conceitos, mas que são centrais para compreender, de maneira aprofundada e central a obra de Gramsci, reflete que o autor desde a juventude desenvolvera um projeto de revolução socialista e de construção de uma nova sociedade, fundamentada até 1920 nos Conselhos de Fábrica.

A autoeducação está diretamente relacionada com a experiência dos jovens ordinovistas $^{5}$, principalmente a partir da publicação de Democraz̧ia Operaia, em 21 de junho de 1919. Na prática,

a democracia proletária começava tão logo a classe operária e seus aliados se mostrassem em condições - dentro da frente única - de constituir institutos autônomos e antagônicos à ordem do capital em condições de se oporem ao poder político do capital na produção e no Estado. (DEL ROIO, 2018, p.37).

Mas, foi a partir da publicação de Democraz̧ia Operaia que a guinada em direção à práxis teve seu início e que os Conselhos de Fábrica passaram a ser muito mais do que um organismo de economia e de política. Foi nesse momento que os jovens de L'Ordine Nuovo começaram a ir às fábricas, assembleias, círculos de cultura e construir, junto com os

\footnotetext{
4 Os embates políticos e teóricos sobre a maneira de enxergar os objetivos do semanário L’Ordine Nuovo e os Conselhos de Fábrica, podem ser encontrados a partir do primeiro número da revista, publicado em $1^{\circ} \mathrm{de}$ maio de 1919. Os principais debates diretos entre Gramsci e Tasca estão presentes na coluna Polemiche sul programma dell'ORDINE NUOVO, a partir das publicações de 1920.

${ }_{5}^{5}$ Antonio Gramsci, Humberto Terracini, Palmiro Togliatti e Angelo Tasca, fundadores de L'Ordine Nuovo.
} 
operários turineses, a democracia operária e um projeto orgânico de transformação da sociedade.

As questões culturais e o princípio educativo - fundamentado na autoeducação e na democracia operária - são de grande importância para o processo de autogestão nas fábricas ocupadas (1920), de maneira que um dos objetivos principais foi o de diminuir a distância entre a escola e a fábrica. É central pensar a relação dialética entre educação do educador na prática teórico-política de L’Ordine Nuovo, momento do qual a crítica de Gramsci, oriunda do

\begin{abstract}
sistema escolar italiano, que enfatizava o ensino técnico destinado aos trabalhadores em busca de emprego ou então o ensino humanista destinado à pequena burguesia, cujo objetivo era compor os diversos escalões da administração pública do Estado liberal-burguês. O desafio era pensar uma escola socialista unitária, que articulasse o ensino técnico-científico ao saber humanista. Essa seria uma chave para que os trabalhadores pudessem perseguir a sua autonomia e desenvolver uma nova cultura, antagônica àquela da burguesia. A luta dos trabalhadores para garantir e aprofundar a cultura, para se apropriar do conhecimento, traria consigo o esforço e o empenho para garantir a autonomia em relação aos intelectuais ${ }^{6}$ e o seu poder despótico. (DEL ROIO, 2018, p.118).
\end{abstract}

A relação estabelecida por L'Ordine Nuovo foi a de educação do educador e não somente de educar o proletariado, com o objetivo principal de apresentar um novo modo de fazer política e de fazer cultura socialista, pois a revista buscava

esclarecer sempre de forma mais concreta que a revolução socialista será executada e se cumprirá com a elaboração e com a instituição de um tipo novo de Estado que reflete a forma da progressiva transformação para mudar a constituição econômica. Acreditamos fazer parte da máxima concretização da obra de cultura, ou seja, de educação revolucionária. (CRONACHE DELL'ORDINE NUOVO, 1919, p.09).

Nesse sentido, a educação está relacionada com a politica e uma nova cultura, o que estabelece a reflexão do nexo proposto entre cultura e americanismo. Para Gramsci, “o movimento pelos Conselhos possuem uma forma e uma finalidade concreta" e foram "compostos pela ação disciplinada e consciente". A luta dos operários deveria ocorrer em diversos frontes: "pela conquista do poder industrial, luta pela conquista das organizações sindicais e pela unidade proletária", tendo como um dos elementos essenciais no processo de desenvolvimento da consciência crítica do proletariado, a autoeducação para a cultura

\footnotetext{
${ }^{6}$ Até 1920 a obra de Sorel é de grande influência para a formação político-intelectual de Gramsci, de forma que questões relativas aos temas do jacobinismo e dos intelectuais é demonstrado por certa "recusa" para Gramsci. Não há um rompimento com Sorel, mas uma superação destas questões que podem ser encontradas, principalmente, no Caderno 13. Note sul Macbiavelli, sulla politica e sullo stato moderno (1977).
} 
crítica, enquanto autodisciplina construída - antes pelo PSI - pelos próprios operários turineses. (GRAMSCI, 1954, p.113).

Portanto, a construção do operaio qualificato precisa estar necessariamente ligada a uma nova cultura que é própria do desenvolvimento da consciência crítica do proletariado, na construção de uma cultura que rompa com as relações e políticas burguesas. A questão da cisão é central nesse debate, pois as classes subalternas precisam forjar seus próprios intelectuais e operários qualificados para gerirem o processo evolucionário e o novo Estado. Dessa maneira,

\begin{abstract}
O conselho deve então ser a base e o fundamento do Estado operário e socialista, das suas instituições sociais. Assim, a escola no Estado de transição deve ser uma escola do trabalho que se emancipa, uma escola que constrói e organiza o trabalho livre associado. Nessa escola, a ação laboriosa disciplinada se articula ao conhecimento da técnica, da ciência e da vasta cultura humanista. $\mathrm{O}$ método e o princípio pedagógico se fundamentam no processo produtivo fabril, coletivo e organizado. (DEL ROIO, 2018, p.121).
\end{abstract}

Em fins de 1920, já no final da revolução italiana, que seria derrotada, principalmente: a) devido ao isolamento dos operários de Turim; b) ausência de apoio do PSI e da CGL no processo de ocupação das fábricas; c) a pressão político-econômica e armada da burguesia, d) os ataques do movimento dos fasci di combattimento, liderados por Benito Mussolini; o grupo de L'Ordine Nuovo organizou uma escola operária que tinha como objetivo principal "que o educador se deixe educar". Com o exercício contínuo e orgânico de "reforçar o princípio de solidariedade e de saber-fazer que era próprio do seu cotidiano de produtores, de incorporar o aprendizado já adquirido no espaço público gerado pela greve, pelo comício, pelo debate.”. É nesse sentido que o “método, a disciplina e a solidariedade próprios do mundo da fábrica deveriam ser a base da escola do trabalho.". (DEL ROIO, 2018, p.122).

Para tanto, os operários de Turim, realizavam um americanismo de novo tipo, de tipo operário, de "educar o proletariado para a autogestão da produção e para a administração pública, entendida como autogoverno", pois "na escola do trabalho é que também seriam lapidados os intelectuais gerados pela própria classe operária, em condições de criar uma nova cultura, distinta e contraposta à da intelectualidade burguesa e mesmo reformista.". (DEL ROIO, 2018, p.122).

A economia e a política estão estritamente interligadas e a revolução política cria um novo ambiente de produção. Para tanto, seria necessário o desenvolvimento da consciência de classes no processo de produção e na nova organização proletária. Essa 
seria, então, a racionalização da classe operária, a organização científica do trabalho e o desenvolvimento técnico da transformação nas formas de produzir. O processo de transformação da psicologia operária se relaciona com o modo de trabalhar e de educação crítica do proletariado, com isso é construído uma consciência crítica e revolucionária que "serve, segundo Gramsci, para romper o nexo de produção/técnica, libertando o modo de produção do vínculo capitalista e formando a nova economia do novo Estado.” (DUBLA, 1986, p.50).

Mas como formar e organizar a subjetividade antagônica da nova consciência no processo de produção?

No artigo Industriali, operai, produrione, publicado no jornal Avanti! , na edição Piemontese de 21 novembro de 1919, Gramsci fala sobre a democracia operária dentro dos Conselhos, sobre como deve ser realizado um censo do poder operário da sessão urbana para que este se torne a sede do Conselho dos delegados da fábrica. O homem deve saber fazer, dar finalidade à produção, isto já modifica seu grau de consciência. Ao produzir, o operário cria direitos, ao intensificar a produção demonstra a potência social do movimento, e "somente na organização de classes é que deve ser fundado o governo da nação.” (GRAMSCI, 1954, p.48).

Essa organização das classes está relacionada com a organização do trabalho e dos trabalhadores que devem ser disciplinados para a construção de um projeto político, econômico e cultural de um novo Estado, de uma nova nação. É dessa maneira que a "hegemonia nasce da fábrica e necessita apenas, para ser exercida, de uma quantidade mínima de intermediários profissionais da política e da ideologia.”. (GRAMSCI, 1977, Q. $22, \S 2$, p.2.146).

Nesse sentido, o americanismo pode ser visto "como o fio vermelho do desenvolvimento capitalista dos "tempos modernos", tanto no sentido econômico, quanto no político-cultural" (BARATTA, 2017, p.38), de forma que possui o significado de "ação real, que modifica essencialmente a realidade exterior (e, portanto, também, a cultura real).”. (GRAMSCI, 1977, Q. 1, $\$ 105$, p.97), pois o americanismo poderia vir a ser uma resposta à demanda da produção constituída pela ação intrínseca entre estrutura econômica, política e cultural com a finalidade de gerir, democraticamente, a vida fabril e pública.

\section{O fascismo}


Os fasci di combattimento surgiram em 1919, na cidade de Milão, com a liderança de Benito Mussolini. ${ }^{7}$ A Itália passava por um grave período econômico-político, causado, principalmente, pelo fim do conflito militar imperialista (1918), somado às derrotas das revoluções socialistas no Leste Europeu. "O Duce funda um fascio de uma espécie nova: o primeiro dos fasci di combattimento, que em seguida passaram a proliferar a Itália inteira" (KONDER, 1977, p. 32.) e ganhava força devido a maior atuação política entre a pequena burguesia, soldados derrotados pela Primeira Guerra Mundial e parte da burguesia italiana.

A análise de Mussolini (1977, p.75) é de que em 1919, "terminada a guerra, o socialismo já era morto como doutrina", mas, "existia somente como rancor.". Dessa maneira, "o fascismo não era sustentado pela necessidade de uma doutrina desenvolvida anteriormente, uma tabela", pois "nasceu de uma necessidade de ação e era ação; ele não era partido, mas nos dois primeiros anos, antipartidário e movimento.". (MUSSOLINI, 1977, p.75).

O movimento fascista cresceu de maneira rápida, atingiu grandes massas entre os setores burgueses e pequeno-burgueses do país, mas Gramsci observava que o movimento armado contra os operários já havia sido antecipado na Espanha e a na Alemanha e não era particular na Itália, de forma que o jovem comunista tornava-se capaz de realizar a análise concreta do movimento reacionário que aos poucos se consolidava. Gramsci não estava errado. Em 1921, o movimento fascista foi assumido como fascismo partidário e excluiu de seu programa o direito de greve dos operários industriais e firmou contato com a monarquia e a Igreja. No verão deste mesmo ano, a violência política, em Turim e nas cidades de maior organização operária, aumentou gradativamente. Preparava-se o terreno para o assalto ao poder e ao Estado, pois é

\footnotetext{
de elementar evidência que os fascistas não querem ser presos, mas, ao contrário, querem usar sua força, toda a força de que dispõem, para se conservar impunes e para alcançar a finalidade máxima de todo movimento: a posse do governo político. (GRAMSCI, 2004, p. 66).
}

O processo de fascistização da sociedade italiana se difundia para diversas esferas da vida social, de maneira que, com o passar do tempo, a consolidação do movimento enquanto ideologia, partido e Estado, acelerava para o capitalismo na Itália e abria portas

\footnotetext{
7 As análises de Gramsci sobre o fascismo podem ser encontradas a partir de 1919, como também em inúmeros artigos de 1920 e 1921, além de constar, mesmo que de maneira fragmentada, nos Cadernos do Cárcere. O objetivo principal na etapa desse trabalho é o de configurar o fascismo a partir dos próprios textos de Mussolini, encontrados em: MUSSOLINI, B. Scritti e Discorsi: dal 1932-1933. Ulrico Hoeppli Editore: Milano, 1977. Contudo, as críticas de Gramsci sobre o fascismo são necessárias - e o leitor as verá ao longo desse item --, por mais que o foco principal seja o de entender a chamada "educação combativa" para Mussolini.
} 
para uma reorganização da burguesia italiana. As mudanças de Mussolini acarretavam diretamente a vida do operário, sendo que em 1927 viria à tona a Carta del'Lavoro que formara um Estado corporativo e que eliminava, teoricamente, as contradições entre capital e trabalho, tendo a configuração de "ditadura do capital financeiro, que se apoia sobre uma ampla rede de organizações de massa, sobre o consenso organizado da maioria da população.”. (COUTINHO, 1999, p.51).

Com a finalidade de organizar a população em torno da ideologia e dos princípios fascistas, o fenômeno reacionário se configurou com o discurso da ética, da espiritualidade, da disciplina e da autoridade, tendo como simbologia a "unidade da força e da justiça.". (MUSSOLINI, 1934, p.73). A questão educacional no fascismo, muito se diferenciava das propostas de autoeducação, cultura e americanismo que levam à emancipação humana que Gramsci defendia. Com a nomeação de Giovanni Gentile, em outubro de 1922, para o Ministério da Instrução Pública, Mussolini foi capaz de unir a questão idealista, por meio de certa liberdade didática, acompanhada do aumento gradativo e intenso do controle autoritário. O apelo de Mussolini, em seus discursos, tinha como objetivo conquistar a população pelo sentimento, na busca da construção de um novo homem, pois

\footnotetext{
o homem do fascismo é o individuo que é nação e pátria, lei moral que mantém indivíduos e gerações unidos em uma tradição e em uma missão que suprime o instinto de vida encerrado no curto passeio de prazer para estabelecer uma vida superior, livre de limites de tempo e espaço: uma vida na qual indivíduo, através da abnegação, faz o sacrifício do interesse totalmente espiritual e conquista seu valor como homem. (MUSSOLINI, 1977, p.68).
}

Nesse sentido, a construção da reforma educacional se tornou de grande importância, em termos de controle para exercício do poder - não apenas armado --, mas psicológico e ideológico, de forma que

\footnotetext{
Os jovens e as crianças surgiram como o alvo principal da política educacional e de propaganda do Fascismo, pois através deles poderiam entrar na vida privada e pública da população italiana. As escolas, as universidades, as associações de trabalhadores (Dopolavoro), o cinema e as organizações da juventude assumiram a função de educar o "novo homem" e de divulgar a cultura política do novo regime. (ROSA, 2009, p.622).
}

Diferente das concepções críticas de Gramsci a respeito da democracia burguesa e da necessidade de construção de uma democracia operária, oriunda, fundamentada e organizada pela classe operária e campesina, Mussolini (1934, p.67) defendia que "a doutrina do fascismo constitui a base fundamental e sintética de qualquer estudo, histórico ou teórico e sua essência e o desenvolvimento do pensamento e da prática fascista", pois o 
fascismo rejeita na democracia a mentira absurda convencional do igualitarismo político, do hábito de irresponsabilidade coletiva, do mito da felicidade e do progresso indefinido. Mas, se a democracia pode ser de outra maneira intensa, isto é, se a democracia significa não rejeitar os povos nas margens do estado, o fascismo pode ser definido como uma democracia organizada, centralizada, autoritária. (MUSSOLINI, 1934, p.81).

Dessa forma, segundo Mussolini, o fascismo possui uma concepção positiva da vida e uma concepção crítica, de maneira que está relacionado com uma concepção espiritual e religiosa, pois o homem deve obedecer a uma "lei superior, com uma Vontade objetiva que transcende o indivíduo particular e o eleva a membro consciente de uma sociedade espiritual.". Dessa forma, o fascismo não é apenas um "sistema de governo, é também, e primeiro de tudo, um sistema de pensamento.". O dever do homem fascista deve estar relacionado com o "grupo familiar e social, na nação e na história", pois o fascismo é "contra a base material (...) é contra todas as utopias e as inovações jacobinas.". (MUSSOLINI, 1977, p.70).

Segundo Gramsci, a tese comunista deveria defender que o fim do fascismo, enquanto fenômeno geral,

\footnotetext{
enquanto flagelo que supera a vontade e os meios disciplinares dos seus líderes, com sua violência, com seus monstruosos arbítrios, com suas destruições tão sistemáticas quanto irracionais, só pode ser extirpado por um novo poder de Estado, por um Estado "restaurado" tal como o entendem os comunistas, ou seja, por um Estado cujo poder esteja nas mãos do proletariado, a única classe capaz de reorganizar a produção e, em consequência, todas as relações sociais que dependem das relações de produção (GRAMSCI, 2004, p. 58).
}

Mas, o desenvolvimento do fascismo, enquanto ideologia de controle e poder às classes subalternas, de aceleração a uma nova etapa do capitalismo, tornara-se uma doutrina política que transporta "o espírito antipacifista" também para a vida dos indivíduos, pois o fascismo se considera um ato de filosofia e de "educação de combate" que modifica, além do Estado, o estilo de vida da população. (MUSSOLINI, 1977, p.75).

É nesse sentido que o fascismo veio a se tornar um dos fenômenos políticos mais significativos do século XX e, que ainda hoje, nos auxilia na compreensão de fenômenos mais recentes, mas que contam ideologicamente com o conservadorismo ou com o regresso aos "tempos antigos", como é o caso - não apenas -- do grupo norte-americano Iluminismo das Trevas, que tem como pressuposto ser um movimento antidemocrático e reacionário que apoiam a monarquia e outras formas de governos centralizadores e antidemocráticos. 


\begin{abstract}
A tese fundamental destes reacionários é a de que todos os males da cultura feminismo, ação afirmativa, liberação sexual, direitos LGBTQ, decadência da educação tradicional e ambientalismo - são responsabilidade da insidiosa influência da Escola de Frankfurt. Lukács e Gramsci também são os responsáveis, mas têm peso menor porque não imigraram para os Estados Unidos. (COSTA, 2019, p.14).
\end{abstract}

Contudo, é necessário compreender que "nem todo movimento reacionário" é "fascista" e que "nem toda repressão - por mais feroz que seja - exercida em nome da conservação de privilégios de classe ou casta é fascista.". No entanto, "o conceito de fascismo não se deixa reduzir, por outro lado, aos conceitos de ditadura ou de autoritarismo", por mais que as "formações sócio-políticas contemporâneas" recorram "sistematicamente ao terror contra-revolucionário, o conceito pode se prestar a equívocos.". No entanto, é devido lembrar que Mussolini e Hitler "conquistaram um lugar no próprio centro da história do nosso século, como pioneiros de uma nova concepção política da direita" e isso nos serve como bagagem histórica para compreender o contemporâneo. (KONDER, 1977, p.05).

\title{
Gramsci em meio à crise brasileira
}

A extrema-direita brasileira reivindica, atualmente, como de sua autoria, o discurso de anticorrupção e a necessidade de ser classe dominante, com a finalidade de não deixar o comunismo avançar no Brasil. Alguns grupos, influenciados por Olavo de Carvalho, se encaixam na ala que denomino como 'antigramsciana'. Em um primeiro olhar, o discurso que se assemelha com algumas características de fascismo, ganha força com a figura cesarista/regressiva de Jair Bolsonaro. As políticas e projetos econômicos neoliberais de seu Governo expressam a tendência de uma nova etapa do neoliberalismo e de reestruturação da crise orgânica do Capital. Tal tendência têm afetado fortemente as estruturas da sociedade burguesa nas diversas instituições: forças armadas, escolas, presídios, igrejas, além dos grupos sociais prejudicados que compõem a classe trabalhadora brasileira.

Dessa maneira, é possível compreender que a prática política da extrema-direita brasileira utiliza o imaginário anticomunista -- originário no Brasil desde meados de 1917 e desenvolvido durante nossos anos de ditaduras -- para reascender algo inviável, hoje, em nosso país: o comunismo, enquanto ameaça. $O$ pânico vermelho retorna ao Brasil no formato do marxismo cultural - teoria conspiratória criada nos Estados Unidos, a partir dos anos 90 -- com uma nova roupagem, o discurso ganha forma na ideologia do gramscismo cultural. 
Que não há gramscismo cultural em Gramsci, os estudiosos e leitores do sardo notam com obviedade. Mas, o que compõe a ideologia do gramscismo? E o que implica quando a extrema direita reivindica essa teoria da conspiração e a utiliza enquanto ideologia de distorção da realidade - para aprovar os projetos neoliberais que assolam a vida dos trabalhadores --? O boom da extrema-direita, em diversos países, representa um movimento orgânico - relativamente permanente - da sociedade ou um fenômeno de conjuntura, composto por ocasiões, imediatismos e quase acidental? ${ }^{8}$

Não há dúvidas que a conjuntura brasileira vive um de seus piores momentos, podendo extrapolar, cada vez mais, para a ausência da democracia burguesa e fraqueza das instituições que mantém, minimamente, o Estado de direito. Gramsci é um dos autores menos conhecido, em termos teóricos, e, possivelmente, o mais distorcido pelos fãs de Bolsonaro. Basta uma pesquisa na internet para conhecer um Gramsci que teve o objetivo, enquanto preso, de fazer uma lavagem cerebral e iniciar uma revolução cultural. Ou seja, transformar as estruturas da sociedade e se apropriar do Estado por meio da educação, da cultura, das escolas e das Universidades. Este seria, nas palavras de Olavo de Carvalho (2014, p.26), o “empreendimento gramsciano de devastação cultural” oriundo do momento de "crise profunda da inteligência", que é um "reflexo" do "deslumbramento apalermado com que recebemos e enaltecemos, como altas produções do espírito, as idéias mais sonsas e descabidas que nos chegam do estrangeiro". O fenômeno que Olavo de Carvalho tenta explicar é o marxismo cultural e a revolução gramscista.

\begin{abstract}
O fantasma do marxismo cultural, já com este nome, teve uma segunda encarnação nos Estados Unidos do início dos anos de 1990, coincidindo com a publicação de estudos críticos e denúncias sobre as ações americanas de contrainsurgência - ou combate a comunistas - principalmente na América Central $^{9}$, e em especial na Colômbia. (COSTA, 2019, p.08).
\end{abstract}

De tal maneira, o marxismo cultural se manifesta como a "própria subversão da cultura ocidental (...) que provém de um pântano de demagogos de extrema direita, totalmente desinformados e muito deficientes no quesito lógica.". O red scare, pânico vermelho, pode ser compreendido como uma guerra declarada e de campanha midiática que promovia o ódio e o medo aos comunistas, iniciada pela lei Espionage Act, criada pelos Estados Unidos, em 1917. O red scare, oficialmente, é acabado em 1921, mas “a execução de Sacco e Vanzetti no dia 23 de agosto de 1927 - é o verdadeiro ponto final desta

\footnotetext{
${ }^{8}$ Estas questões se formam no texto sem, nesse momento, serem respondidas. Mas, chamo atenção para a necessidade de análise da conjuntura brasileira e de respostas ao tempo que nos aflige.

${ }^{9}$ Chomsky dedica várias obras ao tema, inclusive a já citada Propaganda and the Public Mind.
} 
campanha.”. Após esse período, o capital busca diversas formas de reestruturação e de ofensiva às classes subalternas, organizadas em movimentos populares, Partidos políticos e Sindicatos. Será nos anos 60, com o macarthismo, que a ofensiva capitalista se manifesta na luta "contra a infiltração comunista na administração pública, no sistema educacional e na indústria cultural.”. (COSTA, 2019, p.09-14).

Inacabado, o red scare passa por novas transformações em suas táticas e discursos. Para Iná Camargo Costa (2019, p.11), os herdeiros do movimento estiveram presentes na eleição de Ronald Reagan com a "campanha publicitária do neoliberalismo". Contudo, "a hegemonia então reconquistada foi abalada com a crise instaurada em 2008, e ainda hoje em curso, mas persiste aos trancos e barrancos.". Nesse sentido, desde a década de 1990, há uma "versão muito pálida dos dois primeiros, mas não menos ameaçador, pois já conseguiu até eleger o atual presidente daquele país", do Brasil e de outros países da América Latina.

\footnotetext{
A expressão "marxismo cultural" desfruta da duvidosa honra de ter entrado na cena oficial brasileira através do programa da campanha de Bolsonaro à presidência da república em 2018 (disponível na internet), desde já contando com os bons serviços de Steve Bannon, como sabem todos os que acompanharam aquela momentosa operação política. Por esta determinação, nem ao menos merece ser tratada como item separado. Em outras palavras: não passa de extensão à neocolônia (por opção) da pauta metropolitana, graças ainda aos bons serviços da alfândega ideológica instalada no Estado da Virginia, responsável pela péssima tradução dos dogmas americanos. Isto também explica a profundidade de pires das suas manifestações por estas plagas. (COSTA, 2019, p.14).
}

A presença do discurso conspiratório do marxismo cultural no governo Bolsonaro, parcialmente apresentado por Olavo de Carvalho com a figura de um Gramsci que nunca existiu, demonstra que o gramscismo cultural é fruto do marxismo cultural e uma espécie de consciência invertida da realidade. Tem como objetivo primário, levar à população ao medo, ao pânico e ao terror. Contém, como objetivo principal, fortalecer a hegemonia das classes dominantes brasileiras, a acumulação de capital e as incrustações de políticas-econômicas neoliberais em diversos formatos pelo governo: emendas de Leis, Reformas na esfera do trabalho, da educação, além de diversas Medidas Provisórias utilizadas com finalidades político-ideológicas.

Segundo Olavo de Carvalho (2014, p.81), para compreender a "cena brasileira", um dos deveres é "começar a desenhá-lo tomando como centro um personagem que nunca esteve aqui" e que, poucos brasileiros ouviram falar, "mas que, desde o reino das sombras, dirige em segredo os acontecimentos nesta parte do mundo.”. Ao se referir a Antonio Gramsci, Olavo de Carvalho prossegue ao dizer que "as esquerdas jamais" pronunciam seu 
nome "sem acrescentar-lhe a menção de que se trata de um mártir" por ser preso pelo regime fascista, "de onde remeteu ao mundo, mediante não sei que artifício, os trinta e três cadernos de notas que hoje constituem, para os fiéis remanescentes do comunismo brasileiro, a bíblia da estratégia revolucionária.". Gramsci seria então, "o estrategista da revolução psicológica que deve preceder e aplainar o caminho para o golpe de Estado.”. (CARVALHO, 2014, p.83). O comunista, segundo Olavo de Carvalho

\begin{abstract}
concebeu uma dessas idéias engenhosas, que só ocorrem aos homens de ação quando a impossibilidade de agir os compele a meditações profundas: amestrar o povo para o socialismo antes de fazer a revolução. Fazer com que todos pensassem, sentissem e agissem como membros de um Estado comunista enquanto ainda vivendo num quadro externo comunista. Assim, quando viesse o comunismo, as resistências possíveis já estariam neutralizadas de antemão e todo mundo aceitaria o novo regime com a maior naturalidade. (CARVALHO, 2014, p.83).
\end{abstract}

No entanto, para Gramsci $\left(Q .4, \int 75\right.$, p.515, 1977), a reforma intelectual e moral deve ser compreendida na esfera da totalidade, compreendida como a capacidade de envolver as classes subalternas no processo revolucionário, para que elas se tornem protagonistas da transformação social. O processo revolucionário necessita que as classes dominadas desenvolvam o espírito de cisão, de ruptura com a cultura, ideologia e modo de produção capitalista. Para tanto, é um movimento que deve ser fundamentado no "envolvimento ativo" que precisa romper com os setores tradicionais da sociedade "como é aquele dado pela divisão da sociedade entre setores dirigentes e setores subalternos, entre intelectuais e povo.”. Esse processo nada tem relação com a lavagem cerebral descrita por Olavo de Carvalho. Ao contrário. É um processo de construção e desenvolvimento da consciência crítica, de transformação da cultura, de produção e da maneira que o processo produtivo ocorre na produção capitalista.

De fato, Gramsci utiliza as categorias de reforma intelectual e moral, de revolução cultural e de revolução popular com a finalidade revolucionária e de criação de uma nova sociedade. A questão principal é que Gramsci escreve o devir e elabora um projeto revolucionário para seu tempo, do qual podemos extrair categorias e análises ainda atuais, principalmente ao que se refere à luta antagônica ao capital.

Mas o problema está na própria extrema-direita. Ela se resume no fim das contas a uma manipulação racional da irracionalidade de seus seguidores. Isso impede qualquer sofisticação teórica. Seus ideólogos não podem ser profundos, apenas técnicos ou criadores de palavras de ordem simplórias, boatos e conspirações. Daí a glorificação do "especialista" e o desprezo pela Filosofia, enquanto a História se torna palco de disputas entre a "verdade sufocada" e a "manipulação" promovida pela quase totalidade dos historiadores profissionais. (SECCO, 2019). 
A teoria conspiratória, que se torna ideologia para a extrema-direita brasileira, atualiza Gramsci de uma maneira equivocada, pois coloca o Brasil como se vivesse uma guerra cultural contra a esquerda petista. Bolsonaro surge como o líder carismático, do politicamente incorreto, guiado por Deus e por seu Guru, se tornando o salvador do país: o mito. No entanto, sua figura expressa um tipo de cesarismo regressivo indicado pela "influência do elemento militar" ${ }^{10}$. O elemento militar se caracteriza no governo Bolsonaro no sentido da polícia ampliada - possível observar sua militância digital e suas táticas de ataque aos contrários -- e pode ser visto, a partir de análise gramsciana, "não apenas do serviço estatal destinado à repressão da delinquência, mas do conjunto das forças organizadas pelo Estado e privadamente para tutelar o domínio da classe dirigente.”. (GRAMSCI, Q.9, \$133, p.1195, 1977).

Dessa maneira, o discurso do gramscismo se mantém e é fortalecido a cada nova crise no governo. Contudo, "é a auto-descrição dos seus próprios criadores. A caricatura do pensamento do outro existe porque as teorias conspiratórias são basicamente fetichistas", contém o "uso de técnicas ideológicas de penetração cultural nos meios de comunicação para difundir a ideia de que há um núcleo conspiratório "marxista cultural" (...) Os “Gramscistas” são eles mesmos.”. (SECCO, 2019).. .

\section{Considerações finais: a saída gramsciana}

A atualidade do pensamento de Gramsci não se detém na leitura equivocada que tantos ideólogos fazem do sardo. A teoria política gramsciana inova no sentido de nos fazer refletir sobre a possibilidade real de transformação da sociedade, de compreensão dos movimentos da história e do tempo presente. Além de contribuir para novas pesquisas, nas diversas áreas das Ciências Humanas e Ciências Sociais, com o objetivo de explorar novos temas para responder questões antigas ou novas. $\mathrm{O}$ que me detenho, portanto, como parte final desse artigo, é refletir que a democracia operária é, possivelmente, a parte mais importante da teoria gramsciana, que nos faz observar a necessidade de construção de uma democracia de novo tipo, a partir de uma nova cultura - do americanismo de tipo

\footnotetext{
${ }^{10}$ Ver os livros do General Sérgio Augusto de Avellar Coutinho.

11 Artigo de Lincoln Secco, publicado pelo Blog da Boitempo em 08/05/2019. Não consta número de Página. $\quad<<$ https://blogdaboitempo.com.br/2019/05/08/gramscismo-uma-ideologia-da-extremadireita/\# ftn6 $>>$

Site acessado em 29/11/2019.
} 
operário/subalterno - para o desenvolvimento da consciência crítica e de uma nova forma de sociabilidade. 


\section{Referências}

CARVALHO, O. A nova era e a revolução cultural-Fritjof Capra e Antonio Gramsci. Vide: 2014.

O imbecil coletivo-atualidades inculturais brasileiras. Faculdade da

Cidade Editora. Sétima Edição, 1999.

COUTINHO, Carlos Nelson. Gramsci: um estudo sobre seu pensamento político. Rio de Janeiro: Civilização Brasileira, 1999.

COUTINHO, Sérgio. A revolução gramscista no ocidente: a concepção revolucionária de Antonio Gramsci em os Cadernos do Cárcere. Rio de Janeiro:

Estandarte, 2002.

COMMETTI, John. M. Antonio Gramsci e le origini del comunismo italiano. Milano: Mursia, 1974.

COSTA, I. Marxismo cultural, um fantasma que ronda a História. Outras Palavras, 2019.

DEL ROIO, Marcos. Os prismas de Gramsci: a fórmula política da Frente Única (1919-1926). São Paulo: Xamã, 2005.

Gramsci e a emancipação do subalterno. São Paulo: Editora Unesp, 2018.

DUBLA, Ferdinando.Gramsci e la fabbrica: produzione, tecnica e organizzazione del lavoro nel pensiero gramsciano (1913-1934). Manduria: Lacaita, 1986.

GRAMSCI, A. Scritti Politici: la guerra, la rivoluzione e i nuovi problemi del socialismo italiano (1916-1919). A cura di Paolo Spriano. Roma: Riuniti, 1973.

, L’Ordine Nuovo (1919-1920): Opere di Antonio Gramsci. Roma:

Einaud, 1954.

, Quaderni del Carcere. Edizione Critica dell'Istituto Gramsci. A cura di Valentino Gerratana. Roma: IGS, 1977.

Escritos Políticos (1921-1926). Rio de Janeiro: Civilização Brasileira, 2004.

KONDER, L. Introdução ao fascismo. Rio de Janeiro: Graal, 1977.

L'Ordine Nuovo: ressegna settimanale di cultura socialista. Anno 01, N.01, $1^{\circ}$ de maggio, 1919.

MUSSOLINI, B. Scritti e Discorsi: dal 1932-1933. Ulrico Hoeppli Editore: Milano, 1977. 
ROSA, Cristina. Pequenos Soldados do Fascismo: a educação militar durante o governo Mussolini. Antíteses. Londrina, vol. 2, n.4, p.621-648, jul./dez. de 2009.

SECCO, L. Gramscismo: uma ideologia da extrema-direita. Blog da Boitempo, 2019.

Recebido em: 06/12/2019

Aceito em: 24/04/2020.

Publicado online em: 26/04/2020 